\title{
Enzyme linked immunosorbent assays with Treponema pallidum or axial filament of $T$ phagednis biotype Reiter as antigen: evaluation as screening tests for syphilis
}

\author{
R V W van EIJK, ${ }^{*}$ H E MENKE,* G J TIDEMAN,* AND E STOLZ $\dagger$
}

From the *National Institute of Public Health and Environmental Hygiene, Laboratory for Bacteriology, Bilthoven, and the $\dagger$ Department of Dermatovenereology, University Hospital Dijkzigt, Rotterdam, the Netherlands

SUMMARY Enzyme linked immunosorbent assays with an ultrasonicate of Treponema pallidum (TP-ELISA) or axial filament of Treponema phagedenis biotype Reiter (AF-ELISA) were developed to detect treponemal antibody.

TP-ELISA and AF-ELISA were compared with the $T$ pallidum haemagglutination assay (TPHA), the fluorescent treponemal antibody-absorbed(FTA-ABS) test, and the Venereal Disease Research Laboratory (VDRL) test for sensitivity and specificity of serodiagnosis of syphilis. A total of 1423 serum samples, 253 from patients with various stages of syphilis, 500 from patients attending a sexually transmitted disease (STD) clinic, and 670 from people without syphilis, were investigated. At all stages of syphilis the sensitivity of the TP-ELISA, the AF-ELISA, the TPHA, and the FTAABS test did not differ significantly, except that the AF-ELISA was less sensitive than the TPHA $(p<0.05)$ for treated syphilis. In primary syphilis, neurosyphilis, and treated syphilis the TP-ELISA and AF-ELISA were significantly more sensitive than the VDRL test $(p<0.05)$. The specificity of all tests was comparable $(\mathrm{p}>0.05)$. The TP-ELISA and AF-ESLISA appear to be good alternatives to the TPHA as screening tests for syphilis. Because of the easy availability of a well defined antigen the AF-ELISA seems to be better suited for large scale testing.

\section{Introduction}

In the Netherlands routine serological screening for syphilis is undertaken for people attending sexually transmitted disease (STD) clinics, blood donors, and pregnant women. The use of the Treponema pallidum haemagglutination assay (TPHA) alone or in combination with the Venereal Disease Research Laboratory (VDRL) test or the rapid plasma reagin (RPR) card test as screening procedure is generally accepted. For reasons of standardisation of test procedures, however, blood banks and laboratories undertaking prenatal screening programmes prefer to use an enzyme linked immunosorbent assay (ELISA) for the serodiagnosis of syphilis.

In 1975 Veldkamp and Visser described an ELISA to detect treponemal antibodies using an ultrasonic preparation of $T$ pallidum as antigen.' Sensitivity and specificity of this ELISA were comparable with those of the fluorescent treponemal antibody-absorbed

Address for reprints: Dr R V W van Eijk, National Institute of Public Health and Environmental Hygiene, Laboratory for Bacteriology, PO Box 1, 3720 BA Bilthoven, the Netherlands

Accepted for publication 14 April 1986
(FTA-ABS) test. Because of these characteristics and the potential for automation those workers suggested the application of the ELISA as a screening procedure for syphilis. Since then other reports have been published establishing the diagnostic value of the ELISA mainly as a confirmatory test for the serodiagnosis of syphilis. ${ }^{2-4}$

Probably because of difficulties in obtaining sufficient amounts of purified $T$ pallidum antigen, however, the ELISA has never been generally introduced and accepted as a standard procedure for syphilis serology. To avoid this difficulty, nonpathogenic cultivable treponemes have been used to isolate antigenic determinants shared with $T$ pallidum. Hardy et al purified the axial filament from Treponema phagedenis biotype Reiter, ${ }^{5}$ and Hardy and Nell described the use of this component as antigen in an ELISA for detecting treponemal antibody. ${ }^{6}$

Using a different approach for antigen isolation, Strandberg Pedersen et al showed that the sensitivity and specificity of an ELISA with axial filament as antigen equalled those of the FTA-ABS. ${ }^{7}$ They indicated that the ELISA may replace current confirmatory tests, such as the FTA-ABS test and the $T$ 
pallidum immobilisation (TPI) test. No comparison, however, was made with the TPHA, the current screening procedure in the Netherlands.

The present study deals with the suitability of the ELISA for routine serological screening for syphilis. We therefore developed an ELISA with an ultrasonicate of $T$ pallidum (TP-ELISA) and an ELISA with the axial filament of $T$ phagedenis biotype Reiter (AF-ELISA) as antigents, and we compared the sensitivity and specificity of these tests with the TPHA, the FTA-ABS test, and the VDRL test.

\section{Patients, materials, and methods}

\section{SERUM SAMPLES}

We used 253 serum samples from patients with syphilis, 500 from healthy blood donors, 150 from patients with clinical and serological evidence of infectious diseases and disorders other than syphilis, and 20 from pregnant women, all from a collection of serum samples stored at $-20^{\circ} \mathrm{C}$. Fresh serum samples in this study consisted of 500 collected from patients who attended a sexually transmitted disease (STD) clinic at the University Hospital in Rotterdam. All serum samples were tested with the TPHA (Japan Lyophilization Company), the FTA-ABS test, ${ }^{8}$ and the VDRL test. ${ }^{8}$ Before being tested all serum samples were heat inactivated at $56^{\circ} \mathrm{C}$ for 30 minutes. The diagnosis and classification of syphilis was made by consideration of clinical and laboratory data according to the following criteria: (1) non-infected: all serological tests for syphilis non-reactive and no history or clinical findings of syphilis; (2) primary syphilis: localised skin or mucosal lesions, or both, alone or in combination with regional lymphadenopathy, the detection of $T$ pallidum in the lesions or in the lymph nodes, or reactive serological tests; (3) secondary syphilis: generalised lesions of the skin or mucosa, or both, alone or in combination with generalised lymphadenopathy, the detection of $T$ pallidum in the lesions, or reactive serological tests; (4) latent syphilis: no clinical signs of syphilis or history of infection, but reactive serological tests; (5) neurosyphilis: neurological disorders in combination with changes in the cerebrospinal fluid (CSF), positive results to TPHA or FTAABS, or both, in combination with VDRL positive CSF, CSF mononuclear cell count (lymphocytes and monocytes) showing more than $5 \times 10^{6} / 1, \mathrm{IgG}$ index 0.7 or more, ${ }^{9}$ IgM index 0.1 or more, ${ }^{9}$ or oligoclonal CSF immunoglobulins; ${ }^{10}$ (6) treated syphilis: diagnosed syphilis, treated according to current treatment regimens and with no evidence of reinfection (serum samples were collected six months to three years after treatment).

ANTIGENS

T pallidum (Nichols strain) was maintained by serial passage in rabbit testes, and the organisms were extracted as described previously. ${ }^{11}$ Treponemes were purified from residual tissue components by Hypaque density centrifugation. ${ }^{12}$ Preparations adjusted to $5 \mathrm{x}$ $10^{9}$ treponemes in $1 \mathrm{ml}$ of phosphate buffered saline (PBS), $\mathrm{pH} 7 \cdot 2$, were sonicated using a Branson sonifier at $20 \mathrm{KHz}, 50 \mathrm{~W}$, four times for 15 seconds with 30 second intervals at $0^{\circ} \mathrm{C}$. Suspensions were centrifuged at $20000 \mathrm{x}$ for 20 minutes, and the supernatants were stored at $-70^{\circ} \mathrm{C}$ until used.

T phagedenis biotype Reiter was cultured in Brewer thioglycolate medium (Difco Laboratories) with 10\% heat inactivated rabbit serum as described previously. ${ }^{13}$ Axial filament of $T$ phagedenis biotype Reiter was prepared essentially as described by Hardy et al. ${ }^{5}$ After polyacrylamide gel electrophoresis (PAGE) in the presence of 2-mercaptoethanol and sodium dodecyl sulphate (SDS), ${ }^{14}$ the axial filament preparation showed four distinct bands with apparent molecular masses of $39,35,34$, and 32 kilodaltons. The axial filament preparation was stored at $-70^{\circ} \mathrm{C}$.

Protein concentrations were measured by the Lowry procedure. ${ }^{15}$

\section{ELISA PROCEDURE}

A volume of $100 \mu \mathrm{l}$ of antigen suspension diluted to the appropriate concentration in PBS was placed in each well of polystyrene microtitre-ELISA plates (Dynatech Laboratories), which were sealed and incubated in a water bath at $37^{\circ} \mathrm{C}$ for three hours. The wells were emptied, and the plates were stored in a plastic box at $4^{\circ} \mathrm{C}$ until needed. Before use, the plates were washed three times with PBS plus $0.05 \%$ polysorbate (Tween) 20 (PBS-T). A volume of $100 \mu \mathrm{l}$ of serum, diluted 1:100 in PBS-T, was added to each well. Positive and negative control serum samples were included in every experiment. The plates were then sealed and incubated in a water bath at $37^{\circ} \mathrm{C}$ for one hour. The plates were washed as before, and 100 $\mu l$ of sheep anti-human immunoglobulin (IgA, IgG, IgM, Fc, and $\mathrm{Fab}$ ) conjugated to horseradish peroxidase (HPR) ${ }^{16}$ and diluted to the appropriate concentration in PBS-T was added to each well. The plates were covered and incubated in the water bath at $37^{\circ} \mathrm{C}$ for one hour and washed as before, and $100 \mu \mathrm{l}$ of a substrate solution containing tetramethylbenzidine $(1.2 \mathrm{mg} / \mathrm{ml})$, hydrogen peroxide $(0.003 \%)$, sodium acetate $(6 \cdot 8 \%)$, and citric acid $(1.4 \%)$ was added to each well. After 10 minutes at room temperature the reaction was stopped by adding $50 \mu \mathrm{l}$ of $3 \mathrm{~mol} / \mathrm{l}$ sulphuric acid. The plates were read on a Multiscan Reader (Titertek) at $450 \mathrm{~nm}$. Wells containing the substrate only were used as controls.

Optimum concentrations of antigen and dilutions of HRP conjugate were measured by chequerboard titrations using a positive and a negative control serum. Protein concentrations of $3 \mathrm{mg} / 1$ for $T$ pallidum 
ultrasonicate and of $5 \mathrm{mg} / \mathrm{l}$ for axial filament and a HRP conjugate dilution of 1:45000 were found to be appropriate .

The total assay precision of both ELISAs was assessed in 80 separate assays by investigating three reference serum samples covering the range of absorbances between $0 \cdot 2$ and $1 \cdot 0$. A coefficient of variation less than $15 \%$ was found for all three serum samples in both ELISAs.

To compensate for variations between assays the absorbance value of each clinical specimen was multiplied by the correction factor required to adjust to its mean value one of the three reference serum samples run on the same plate. The reference serum with an absorbance value nearest to the breakpoint was chosen.

\section{STATISTICAL ANALYSIS}

The sign test was applied to compare the results of the different tests.

\section{Results}

DISTRIBUTION OF ELISA ABSORBANCES IN POSITIVE AND NEGATIVE CONTROL SERUM SAMPLES
To choose a breakpoint to distinguish between a positive and a negative result we compared the distribution of ELISA absorbances of 187 untreated patients with syphilis with that of 500 non-infected people (table I). If the breakpoint for the TP-ELISA was chosen at an absorbance of $0 \cdot 9,1 \cdot 0$, or $1 \cdot 1$ then 11,3 , and 0 serum samples respectively from the non-infected people were found to be positive and 9, 12, and 24 serum samples from the patients with syphilis were negative. At a breakpoint chosen at absorbances of $0.5,0.6$, or 0.7 for the AF-ELISA, 4,1 , and 0 serum samples respectively from non-infected people were positive and 5,13 , and 22 from patients with syphilis were negative.

To ensure a false positive rate less than $1 \%$ and to find a reasonable balance between the number of false positive and false negative results, the breakpoint for the TP-ELISA was set at an absorbance of 1.0 and the breakpoint for the AF-ELISA at $0 \cdot 5$.

\section{COMPARISON OF TP-ELISA AND AF-ELISA}

The reactivities of TP-ELISA and AF-ELISA were compared with the reactivities of the TPHA, FTAABS, and VDRL using 253 serum samples frozen at $-20^{\circ} \mathrm{C}$ from patients with syphilis and 500 from noninfected people (table II). In untreated serum samples

TABLE I Comparison of absorbance values of TP-ELISA and AF-ELISA with 187 serum samples from patients with syphilis and 500 serum samples from non-infected people

\begin{tabular}{|c|c|c|c|c|c|c|c|c|c|c|}
\hline \multirow[b]{2}{*}{ Diagnostic category } & \multirow[b]{2}{*}{ ELISA } & \multicolumn{9}{|c|}{ No of serum samples with absorbances at $450 \mathrm{~nm}$ of: } \\
\hline & & $<0.4$ & $0.4-0.49$ & $0.5-0.59$ & $0.6-0.69$ & $0 \cdot 7-0.89$ & $0.9-0.99$ & $1 \cdot 0-1 \cdot 09$ & $1 \cdot 1-1 \cdot 19$ & $>1 \cdot 2$ \\
\hline Non-infected & TP-ELISA & 225 & 93 & 81 & 52 & 38 & 8 & 3 & 0 & 0 \\
\hline Untreated syphilis & TP-ELISA & 2 & 1 & 1 & 1 & 4 & 3 & 12 & 39 & 124 \\
\hline Non-infected & AF-ELISA & 480 & 16 & 3 & 1 & 0 & 0 & 0 & 0 & 0 \\
\hline Untreated syphilis & AF-ELISA & 4 & 1 & 8 & 9 & 20 & 14 & 14 & 35 & 82 \\
\hline
\end{tabular}

ELISA = enzyme linked immunosorbent assay using Treponema pallidum ultrasonicate (TP) or axial filament of $T$ phagedenis biotype Reiter (AF) as antigen.

TABLE II Results of serological tests for syphilis on serum samples from patients with syphilis and non-infected people

\begin{tabular}{|c|c|c|c|c|c|c|}
\hline \multirow[b]{2}{*}{ Diagnostic category } & \multirow[b]{2}{*}{$\begin{array}{l}\text { No of } \\
\text { serum } \\
\text { samples }\end{array}$} & \multicolumn{5}{|c|}{ No (\%) of serum samples positive by: } \\
\hline & & TPHA & $F T A-A B S$ & $V D R L$ & $T P-E L I S A$ & $A F-E L I S A$ \\
\hline $\begin{array}{l}\text { Primary syphilis } \\
\text { Secondary syphilis } \\
\text { Latent syphilis } \\
\text { Neurosyphilis } \\
\text { Treated syphilis } \\
\text { No syphilis }\end{array}$ & $\begin{array}{r}77 \\
44 \\
35 \\
31 \\
66 \\
500\end{array}$ & $\begin{array}{l}72(93 \cdot 5) \\
44(100) \\
35(100) \\
31(100) \\
66(100) \\
3 \quad(0.6)\end{array}$ & $\begin{array}{lc}73 & (93 \cdot 5) \\
44 & (100) \\
35 & (100) \\
31 & (100) \\
59 & (89 \cdot 4) \\
2 & (0 \cdot 4)\end{array}$ & $\begin{aligned} 49 & (63 \cdot 6) \\
44 & (100) \\
32 & (91 \cdot 4) \\
19 & (61 \cdot 3) \\
28 & (42 \cdot 4) \\
2 & (0 \cdot 4)\end{aligned}$ & $\begin{array}{ll}65 & (84 \cdot 4) \\
44 & (100) \\
35 & (100) \\
31 & (100) \\
60 & (90 \cdot 9) \\
3 & (0 \cdot 6)\end{array}$ & $\begin{array}{ll}72 & (93 \cdot 5) \\
44 & (100) \\
35 & (100) \\
31 & (100) \\
48 & (72 \cdot 7) \\
4 & (0 \cdot 8)\end{array}$ \\
\hline
\end{tabular}

TPHA = Treponema pallidum haemagglutination assay.

FTA-ABS = Fluorescent treponemal antibody absorbed test.

VDRL $=$ Venereal Disease Research Laboratory test.

ELISA = Enzyme linked immunosorbent assay using $T$ pallidum ultrasonicate (TP) or axial filament of $T$ phagedenis biotype Reiter (AF) as antigen. 
from infected patients all tests had similar reactivity except when samples from patients with primary syphilis and neurosyphilis were used. In those with primary syphilis and neurosyphilis the sensitivity of the TP-ELISA and AF-ELISA was identical or comparable with that of the TPHA and FTA-ABS test, but significantly higher $(p<0.05)$ than the sensitivity of the VDRL test.

In patients with treated syphilis the sensitivity of the VDRL test was significantly lower $(p<0.05)$ than that of the other tests. The AF-ELISA was significantly less sensitive $(p<0.05)$ than the TPHA in these patients.

Of the serum samples from 500 non-infected people, thre 2 were positive by the TP-ELISA and four by the AF-ELISA. In comparison the TPHA, the FTA-ABS test, and the VDRL test were positive in three, two, and two cases respectively. The observed differences in specificity were not significant.

To assess the false positive rates in conditions other than syphilis a total of 150 serum samples from patients with various infectious diseases and rheumatoid arthritis were investigated by all tests. In addition 20 serum samples from pregnant women were tested (table III). Three tests, the TP-ELISA, the AFELISA, and the TPHA, did not give positive results. The FTA-ABS and the VDRL gave positive results with two and four serum samples respectively. None of the people from whom these serum samples were taken had evidence of present or past syphilis.

\section{COMPARISON OF TESTS USING FRESH SERUM} SAMPLES

Of 500 fresh serum samples submitted for syphilis serology investigated by the TP-ELISA, the AF-ELISA, the TPHA, the FTA-ABS test, and the VDRL test, 105 gave positive results in one or more of the tests. Table IV shows the number of serum samples giving positive results by each test and combination of tests in relation to the result of a careful evaluation of the patient's history and clinical and laboratory findings. The 92 positive serum samples were from patients diagnosed as having treated ( 88 cases) and untreated (four cases) syphilis: All four patients with untreated syphilis gave positive results in the AF-ELISA, whereas the other tests failed to detect one case of dark field positive primary syphilis. All 88 serum samples from patients who had been treated for syphilis were TPHA and FTA-ABS positive. Incorrect results were given by the TP-ELISA (four samples) and AF-ELISA (20), and the VDRL test (40).

The remaining 13 serum samples giving positive results were from people with neither clinical evidence nor a reliable history of syphilis. Five of them were born in Surinam and gave positive results in the TPHA, the AF-ELISA, or the TPHA and the FTAABS test. Of the four serum samples showing an isolated positive reaction in the TP-ELISA, one was from a person born in Indonesia and three were from promiscuous people born in the Netherlands. In four

TABLE III Results of serological tests for syphilis on serum samples from people with diseases other than syphilis and from pregnant women

\begin{tabular}{|c|c|c|c|c|c|c|}
\hline \multirow[b]{2}{*}{ Diagnostic category } & \multirow{2}{*}{$\begin{array}{l}\text { No of } \\
\text { serum } \\
\text { sample }\end{array}$} & \multicolumn{5}{|c|}{ No of serum samples reactive to: } \\
\hline & & TPHA & $F T A-A B S$ & $V D R L$ & TP-ELISA & $A F-E L I S A$ \\
\hline Chlamydial infection & 10 & & & & & \\
\hline Gonorrhoea & 20 & & & & & \\
\hline Bacterial meningitis & 15 & & & 1 & & \\
\hline Mycoplasmal pneumonia & 10 & & & & & \\
\hline Toxoplasmosis & 10 & & & & & \\
\hline Hepatitis B & 18 & & & & & \\
\hline Rubella infection & 10 & & & & & \\
\hline Varicella infection & 7 & & & & & \\
\hline Herpes infection & 10 & & & 1 & & \\
\hline Adenovirus infection & 10 & & & & ' & \\
\hline Measles & 10 & & 1 & & & \\
\hline $\begin{array}{l}\text { Infectious } \\
\text { mononucleosis }\end{array}$ & 10 & & & & & \\
\hline Rheumatoid arthritis & 10 & & 1 & & & \\
\hline Pregnancy & 20 & & & 2 & & \\
\hline
\end{tabular}

TPHA $=$ Treponema pallidum haemagglutination assay.

FTA-ABS = Fluorescent treponemal antibody absorbed test.

VDRL = Venereal Disease Research Laboratory test.

ELISA = Enzyme linked immunosorbent assay using $T$ pallidum ultrasonicate (TP) or axial filament of $T$ phagedenis biotype Reiter (AF) as antigen. 
TABLE IV Results of serological tests for syphilis in relation to clinical data on 105 positive serum samples

\begin{tabular}{|c|c|c|c|c|c|c|c|c|}
\hline \multicolumn{5}{|c|}{ Results of serological reactions by: } & \multirow{2}{*}{$\begin{array}{l}\text { No (\%) of } \\
\text { serum } \\
\text { samples }\end{array}$} & \multicolumn{2}{|c|}{$\begin{array}{l}\text { No of patients with } \\
\text { known syphilis: }\end{array}$} & \multirow{2}{*}{$\begin{array}{l}\text { No of people with } \\
\text { no clinical evidence } \\
\text { or history of syphilis }\end{array}$} \\
\hline$T P H A$ & $F T A-A B S$ & $V D R L$ & TP-ELISA & $A F-E L I S A$ & & Treated & Untreated & \\
\hline+ & + & + & + & + & $49(46 \cdot 7)$ & 46 & 3 & . \\
\hline+ & + & + & + & - & $2(1.9)$ & 2 & & \\
\hline+ & + & - & + & + & $21(20.0)$ & 21 & & \\
\hline+ & + & - & + & - & $16(15 \cdot 2)$ & 16 & & \\
\hline+ & + & + & - & + & $1(1.0)$ & 1 & & \\
\hline+ & + & - & - & + & $1(1 \cdot 0)$ & 1 & & \\
\hline+ & + & - & - & - & $2(1.9)$ & 1 & & 1 \\
\hline+ & - & - & - & - & $2(1.9)$ & & & 2 \\
\hline - & + & - & - & - & $1(1.0)$ & & & 1 \\
\hline- & - & + & - & - & $3(2 \cdot 9)$ & & & 3 \\
\hline- & - & - & + & - & $4(3 \cdot 8)$ & & & 4 \\
\hline- & - & - & - & + & $3(2.9)$ & & 1 & 2 \\
\hline
\end{tabular}

TPHA $=$ Treponema pallidum haemagglutination assay.

FTA-ABS = Fluorescent treponemal antibody absorbed test.

VDRL $=$ Venereal Disease Research Laboratory test.

ELISA = Enzyme linked immunosorbent assay using $T$ pallidum ultrasonicate (TP) or axial filament of $T$ phagedenis biotype Reiter (AF) as antigen.

Results: $+=$ positive; - $=$ negative

people with either a single positive FTA-ABS test (one) or a single positive VDRL reaction (three) there was no reliable evidence of syphilis.

\section{Discussion}

The results of this study indicate that ELISAs using $T$ pallidum ultrasonicate or axial filament of $T$ phagedenis biotype Reiter as antigen are suitable for serodiagnosis of syphilis. By investigating frozen and fresh serum samples from patients with untreated syphilis and non-infected people we found that the sensitivity and specificity of the TP-ELISA and the AF-ELISA were comparable with those of the TPHA and the FTA-ABS test. Differences were found when testing serum samples from patients with treated syphilis, for which the AF-ELISA was significantly less sensitive than the TPHA. The sensitivity of the TP-ELISA and the AF-ELISA compared favourably with that of the VDRL test in patients with primary syphilis, neurosyphilis, or treated syphilis.

In contrast to the FTA-ABS test and the VDRL test, positive ELISA reactions were not found in serum samples from people with conditions other than syphilis. From the 10 fresh serum samples reactive in the treponemal tests and with no reliable evidence of syphilis, six were from immigrants born in tropical countries and three from promiscuous people born in the Netherlands. Antitreponemal reactivity in this group could have been due to antibody formed against commensal treponemes sharing antigens with $T$ pallidum or the axial filament of $T$ phagedenis biotype Reiter, or both. In promiscuous people, however, it also could reflect earlier exposure to $T$ pallidum.
The overall sensitivity $(93.6 \%)$ and specificity $(99 \cdot 2 \%)$ of the TP-ELISA are in general agreement with sensitivity and specificity values of $99 \%$ and $98 \%,{ }^{1} 89 \%$ and $99 \%,{ }^{2}$ and $96 \%$ and $95 \%{ }^{3}$ that have been reported for ELISAs using $T$ pallidum as antigen.

Though in this study we used different procedures from those used by Strandberg Pedersen $e t$ al to isolate the axial filament of $T$ phagedenis biotype Reiter, ${ }^{7}$ the results from both studies correlated well. This observation corroborates the conclusion of Sand Petersen et $a l^{17}$ that their isolation procedure is qualitatively equal to methods described earlier.

Baughn and Musher purified by SDS-PAGE antigenic components from $T$ phagedenis biotype Reiter that showed cross reaction with $T$ pallidum. ${ }^{18}$ Using a radioimmunoassay these authors found that in contrast with antigens with an apparent molecular mass of between 33 and 64 kilodaltons, the 37 kilodalton material representing the axial filament reacted with serum samples from patients suffering from secondary syphilis but not with samples from patients with primary syphilis. From our data and those of Strandberg Pedersen et al, ${ }^{7}$ however, it became clear that antibodies to axial filament were usually present in patients with primary syphilis. Moreover, from the work of Strandberg Pedersen (19) it appeared that of the antigenic components of $T$ phagedenis biotype Reiter shared with $T$ pallidum, only the axial filament is of value in the serodiagnosis of syphilis. These conflicting data probably reflect the different approaches used to purify the axial filament. The antigenic determinants of this component are possibly partially destroyed by the harsh effects of 
SDS solubilisation and boiling inherent to SDSPAGE.

Compared with the AF-ELISA the breakpoint of the TP-ELISA had to be set at a rather high absorbance value $(1 \cdot 0)$ to discriminate between positive and negative results. By absorbing serum samples from people who did not have syphilis with a sorbent preparation used for the FTA-ABS, high absorbance values could be lowered appreciably. Absorption showed less effect in serum samples from patients with syphilis (data not shown). These findings indicate that high absorbance values in the control serum samples are probably due to cross reacting antibodies caused presumably by commensal treponemes.

Several attempts to produce T pallidum antigens by DNA recombinant technology have been successful. ${ }^{20-22}$ So far these antigens have unfortunately not been shown to be suitable for the serodiagnosis of syphilis. As the production of $T$ pallidum in vivo is tedious and continuous cultures have not been established in vitro the results from this study and that of Strandberg Pedersen el al ${ }^{7}$ show that the axial filament is, at the moment, the best choice of antigen available for use in an ELISA for syphilis.

Compared with the TPHA the AF-ELISA has several advantages: the test can be easily automated; the use of automatic plate readers eliminates the subjectivity of visual reading; the test uses an easily purifiable and defined antigen from a treponeme cultivable in vitro, and the test detects fewer treated cases of syphilis, which are less important from a clinical and epidemiological point of view.

In conclusion, ELISAs using $T$ pallidum ultrasonicate or axial filament of $T$ phagedenis biotype Reiter as antigen seem to be convenient methods for the serodiagnosis of syphilis. Because axial filament is more easily available than $T$ pallidum antigen, the AF-ELISA could be an attractive alternative to the TPHA when large scale testing is required, such as for blood bank or prenatal screening. To establish the suitability of the test for screening these populations, however, much more extensive testing of serum samples is necessary.

We thank $\mathrm{M} J$ van Niekerk and $\mathrm{J} C$ Compeer for carrying out the routine serology test for syphilis and L M Schouls for preparing the axial filament.

\footnotetext{
References

1. Veldkamp J, Visser AM. Application of the enzyme linked immunosorbent assay (ELISA) in the serodiagnosis of syphilis .
} British Journal of Venereal Diseases 1975;51:227-31.
2. Pope V, Hunter EF, Feeley JC. Evaluation of the microenzyme-linked immunosorbent assay with Treponema pallidum antigen. J Clin Microbiol 1982;15:630-4.

3. Farshey CE, Hunter EF, Helsel LO, Larsen SA. Four-step enzyme-linked immunosorbent assay for detection of Treponema pallidum antibody. J Clin Microbiol 1985;21:3879.

4. Stevens RW, Schmitt ME. Evaluation of an enzyme-linked immunosorbent assay for treponemal antibody. J Clin Microbiol 1985;21:399-402.

5. Hardy PH, Fredericks WR, Nell EE. Isolation and antigenic characteristics of axial filaments from the Reiter treponeme. Infect Immun 1975;11:380-6.

6. Hardy PH, Nell EE. An enzyme-linked immuno specific assay for diagnosis of syphilis. Abstracts of the American Society of Microbiology 1978;C190:308.

7. Strandberg Pedersen N, Sand Petersen C, Vejtorp M, Axelsen $\mathrm{NH}$. Serodiagnosis of syphilis by an enzyme-linked immunosorbent assay for IgG antibodies against the Reiter treponeme flagellum. Scand J Immunol 1982;15:341-8.

8. US Public Health Service. Manual of tests for syphilis. Washington DC: US Department of Health, Education and Welfare, US Government Printing Office 1969 (PHS Publication No 411):1-77.

9. Link H, Wahren B, Norrby E. Pleocytosis and immunoglobulin changes in cerebrospinal fluid and herpes virus serology in patients with Guillain-Barré syndrome. J Clin Microbiol 1979;9:305-16.

10. Van der Helm HJ, Hische EAH, Van Walbeek HK. Monoclonal immunoglobulins demonstrable in cerebrospinal fluid by use of cellulose acetate electrophoresis. Clin Chem 1980;26:1917-8.

11. Miller JH, De Bruijn JH, Bekker JH, Onvlee PC. The antigenic structure of Treponema pallidum, Nichols strain. I. The demonstration, nature, and location of specific and shared antigens. J Immunol 1966;96:450-6.

12. Baseman JB, Nichols JC, Rumpp JW, Hayes NS. Purification of Treponema pallidum from infected rabbit tissue: resolution into two treponemal populations. Infect Immun 1974;10:10627.

13. De Bruijn JH. A simplified method for the preparation of Reiter protein antigen. Antonie van Leeuwenhoek 1960;26:317-20.

14. Laemmli UK. Cleavage of structural proteins during the assembly of the head of bacteriophage T4. Nature 1970; 227:680-5.

15. Lowry OH, Rosebrough NJ, Farr AL, Randall RJ. Protein measurement with the Folin phenol reagent. $J$ Biol Chem 1951;193:265-75.

16. Nakane PK, Kawaoi A. Peroxidase-labelled antibody, new method of conjugation. J Histochem Cytochem 1974;22:108494.

17. Sand Petersen C, Strandberg Pedersen N, Axelsen NH. A simple method for the isolation of flagella from Treponema reiteri. Acta Pathol Microbiol Scand [C] 1981;89:379-85.

18. Baughn RE, Musher DM. Radioimmunoassays for the detection of antibodies to treponemal polypeptide antigens in serum.J ClinMicrobiol 1985;21:922-9.

19. Strandberg Pedersen $H$. Treponemal antigens and their use in syphilis serological tests. Dan Med Bul 1984;31:227-39.

20. Walfield AM, Hanff PA, Lovett MA. Expression of Treponema pallidum antigens in Escherichia coli. Science 1982;216:522-3.

21. Stamm LV, Folds JD, Bassford PJ. Expression of Treponema pallidum antigens in Escherichia coli K-12. Infect Immun 1982;36:1238-41.

22. van Embden JDA, van der Donk HJ, van Eijk RVW, et al. Molecular cloning and expression of Treponema pallidum DNA in Escherichia coli K-12. Infect Immun 1983;42:18796. 